\title{
Die Zieffitsgnumd/äk̨e
}

oss

Sionigl. Z̊reufigiffien

\section{(1)her-permaltungfgexidts.}

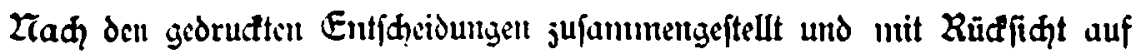
die fortfhreitcude und auf dic menen Provingelt ausgedehnte Derwaltungs: zefecţgibung erlāutert

volt

\&. Z⿱乛龰are1),

1Königl. Werwaltungsgeriats · Direftor a. $\mathfrak{D}$.

$2^{\text {it }}$ bermebrte und verbefferte Fuflage.

\section{Grgïnzungghand 1893}

enthaltend die Red̨tsgrumdiäbe aus Bano XXIII und XXIV fomic als Bano I der Entfalcionngen in Stellerjadten.

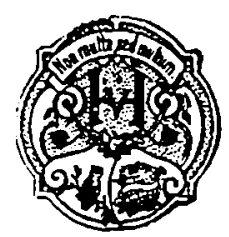

Zserftin 1894.

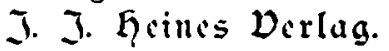


